Article

\title{
Aluminum Nitride Ceramic as an Optically Stimulable Luminescence Dosimeter Plate
}

\author{
Go Okada ${ }^{1, *}$, Kentaro Fukuda ${ }^{2}$, Safa Kasap ${ }^{3}$ and Takayuki Yanagida ${ }^{1}$ \\ 1 Graduate School of Materials Science, Nara Institute of Science and Technology (NAIST), \\ 8916-5 Takayama-cho, Ikoma, Nara 630-0192, Japan; t-yanagida@ms.naist.jp \\ 2 Tokuyama Corporation, 1-1 Mikage-cho, Shunan-shi, Yamaguchi 745-8648, Japan; \\ ken-fukuda@tokuyama.co.jp \\ 3 Department of Electrical and Computer Engineering, University of Saskatchewan, 57 Campus Dr., \\ Saskatoon, SK S7N 5A9, Canada; safa.kasap@usask.ca \\ * Correspondence: go-okada@ms.naist.jp; Tel.: +81-743-72-6144
}

Received: 4 April 2016; Accepted: 27 April 2016; Published: 30 April 2016

\begin{abstract}
Photostimulable storage phosphors have been used in a wide range of applications including radiation measurements in one- and two-dimensional spaces, called point dosimetry and radiography. In this work, we report that an aluminum nitride (AlN) ceramic plate, which is practically used as a heat sink (SHAPAL ${ }^{\circledR}$, Tokuyama Corp., Yamaguchi, Japan), shows good optically-stimulated luminescence (OSL) properties with sufficiently large signal and capability for imaging applications, and we have characterized the AIN plate for OSL applications. Upon interaction with X-rays, the sample color turns yellowish, due to a radiation-induced photoabsorption band in the UV-blue range below $\sim 500 \mathrm{~nm}$. After irradiating the sample with X-rays, an intense OSL emission can be observed in the UV $(360 \mathrm{~nm})$ spectral region during stimulation by red light. Although our measurement setup is not optimized, dose detection was confirmed as low as $\sim 3$ mGy to over 20 Gy. Furthermore, we have successfully demonstrated that the SHAPAL ${ }^{\circledR}$ AlN ceramic plate has great potential to be used as an imaging plate in radiography.
\end{abstract}

Keywords: AlN; OSL; dosimeter; X-rays

\section{Introduction}

Ionizing radiations such as X-rays, gamma-rays, alpha-rays, etc., may be measured using various techniques. One of the common techniques is to use phosphors [1]. The phosphor materials have functionalities to convert radiation to light so that one can indirectly measure the radiation using conventional photodetectors such as charge-coupled device (CCD), complementary metal-oxide semiconductor (CMOS), and photomultiplier tube (PMT) [1]. Rapid light emission upon the absorption of radiation can be typically used for real-time measurements, and such phosphors are so-called scintillators [2-4]. On the other hand, another type of radiation phosphor can accumulate and store the incident dose information in the form of trapped charges, which can be read out optically or thermally. Such phosphors are commonly referred to as so-called storage phosphors or dosimeters. The latter materials are used in practice in a wide range of areas such as medical imaging $[5,6]$, radiation therapies [7], personnel dose monitoring [8] and so on.

The mechanisms involved in dosimeter materials are typically but intuitively understood as follows. First, a numerous number of electrons and holes are generated upon the absorption of an incident of ionizing radiation, and then some of those charges are captured by localized trapping centers, and the captured carriers remain trapped over the experimental time scale; the stored charge is stable. These trapped charges can be detrapped by an external stimulation in the form of, in general, heat or light. As a result, the freed charges then recombine at luminescent centers followed by a light 
emission. Since the emitted light output is proportional to the incident radiation dose, the stimulated light emission may be indirectly used as a probe of the incident radiation dose. Dosimeters which use heat to stimulate the signal are so-called thermally stimulated luminescent detectors (TLD) [9], while the ones which rely on an optical stimulation are referred to as optically stimulated luminescent detectors (OSLD) [10-13]. Examples of dosimeter materials used in practice include LiF:Mg, Ti [14], $\mathrm{Al}_{2} \mathrm{O}_{3}: \mathrm{C}[15,16]$, and $\mathrm{BeO}$ [17]. These materials do indeed show excellent properties for dose detection such as high sensitivity and stability of dose information during storage. In addition, it is a key requirement for dosimeter materials to consist of light chemical compositions that are equivalent to tissue in order for the radiation to interact with the dosimeter material in the same way as it does for tissue, and the dose measurement accuracy is maintained to be high.

Aluminum nitride $(\mathrm{AlN})$ is of our current interest to be studied as a dosimeter material due to its useful properties. It has a wide optical band-gap $(\sim 6.2 \mathrm{eV})$ and is used in UV-emitting LEDs [18]. Also, it has high thermal conductivity and it is an electrical insulator; it is practically used as a heat sink. In terms of the interactions with X-rays, AlN is considered to be equivalent to tissue as the effective atomic number of $\mathrm{AlN}$ (11.7) is considerably low and very similar to well-accepted $\mathrm{Al}_{2} \mathrm{O}_{3}$-based dosimeters. Earlier, we reported that an AlN ceramic plate (SHAPAL ${ }^{\circledR}$, Tokuyama Corp., Yamaguchi, Japan), which is in fact a commercial product as a heat sink, shows thermally-stimulated luminescence (TSL) properties and it has a good potential to be used as a TLD dosimeter [19]. In this work, in contrast, we have newly discovered that the SHAPAL ${ }^{\circledR}$ AlN ceramic plate also exhibits optically-stimulated luminescence (OSL) properties. The aim of this work is to characterize the AlN plate as an OSL dosimeter material and to show its ability in practical use such as personnel dose monitoring and dose distribution measurements. Our experimental results are provided in this paper.

\section{Experimental Procedure}

AlN ceramic plates studied in this work were manufactured by Tokuyama Corp., Yamaguchi, Japan, and these are, in fact, commercially available as SHAPAL ${ }^{\circledR}$ for heat sink applications. The samples were then characterized at the Nara Institute of Science and Technology (NAIST) towards OSL dosimeter applications. The typical sample size used in the investigations was $15 \times 10 \times 0.65 \mathrm{~mm}^{3}$. The optical transmittance spectrum was measured using a spectrophotometer (SolidSpec-3700, Shimadzu, Kyoto, Japan). The OSL emission spectra were measured using the Hamamatsu Quantaurus-Tau (C11367, Shizuoka, Japan). A spectrofluometer (FP-8600, JASCO, Tokyo, Japan) was used to study the OSL stimulation spectra and the afterglow of OSL emission. During the measurements, a $340 \mathrm{~nm}$ band-pass filter was inserted at the detector side, and stimulation light was delivered through a $400 \mathrm{~nm}$ short-cut filter in order to avoid an interference of a second-order diffraction light. The samples were irradiated using an X-ray generator (Model XRBOP\&N200X4550, Spellman, Hauppauge, NY, USA), which is equipped with a W anode target with the Be window. All the irradiations were carried out with the tube voltage of $40 \mathrm{kVp}$ with the filament current of $5.2 \mathrm{~mA}$. To demonstrate the AIN ceramic plate for use as an X-ray imaging plate, an original measurement setup was constructed in our laboratory. A large size AlN plate $59 \times 38 \mathrm{~mm}^{2}$ was irradiated by X-rays through electronic integrated circuits. After the irradiation, the AlN plate was exposed to stimulation light at a wavelength of $\sim 630 \pm 50 \mathrm{~nm}$ from a Xenon lamp (LAX-C100, Asahi Spectra, Tokyo, Japan), then the 2D OSL distribution was measured by a Peltier-cooled CCD camera (BK-54DUV, Bitran Corp., Saitama, Japan) equipped with an objective lens (PF10545MF-UV, Nikon, Tokyo, Japan).

\section{Results and Discussion}

The AlN plate used in this research is illustrated in Figure 1 (left). These ceramics can be fabricated homogeneously over a relatively large area as can be confirmed in the photograph. The latter feature is of fundamental interest, especially for two-dimensional radiation imaging. The size of the AlN plate in the photograph is $59 \times 38 \mathrm{~mm}^{2}$ with a thickness of $0.65 \mathrm{~mm}$. As a commercial product (as a heat sink), it is currently available as large as $\sim 120 \times 120 \mathrm{~mm}^{2}$ but it is certainly possible to fabricate AlN in a larger 
area. The color of the AlN plate is light grey as provided. However, once it is irradiated by X-rays, it turns into a yellowish color. The color change is, in fact, due to the appearance of photoabsorption bands which are strongly induced by the X-ray irradiation, and appear in the UV-blue range (shorter than $\sim 500 \mathrm{~nm}$ ). The X-ray-induced absorbance spectra are illustrated in Figure 1 (right). A significant absorption is observed in the range of $250-550 \mathrm{~nm}$. The induced absorbance increases as a function of the irradiated dose. We think that it is due to the common effect of radiation-induced color centers created by the irradiation; however, detailed studies are required in order to determine the origin of these induced color centers.
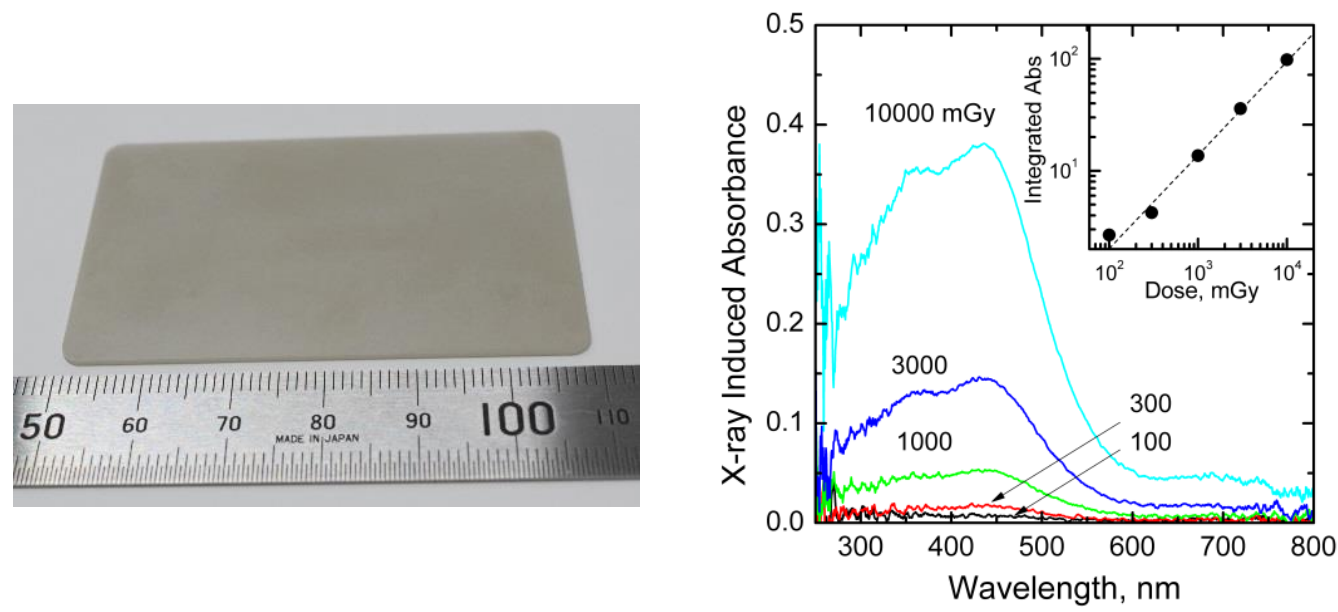

Figure 1. (left) AlN ceramic plate $\left(\mathrm{SHAPAL}^{\circledR}\right)$ manufactured by Tokuyama Corp. (right) X-ray-induced absorbance as a function of X-ray dose irradiated. The inset is the integrated absorbance signal vs. the corresponding dose.

After X-ray irradiation, an OSL emission is observed in the UV range when stimulated by red light. The emission spectrum is illustrated in Figure 2. The irradiation dose was $20 \mathrm{~Gy}$. The emission signal has a broad spectral feature peaking around $360 \mathrm{~nm}$, while the sample is stimulated by $630 \mathrm{~nm}$. Further, there seems to be a very small emission band with the peak around $505 \mathrm{~nm}$, but the latter emission is found to be negligibly small compared to the UV emission. It is instructive to mention here that, interestingly, the OSL was also observed after a UV $(254 \mathrm{~nm})$ irradiation. A similar emission was previously observed at $\sim 340 \mathrm{~nm}$ in radioluminescence [19] and in cathodoluminescence [20-22]; however, as far as we are aware, the origin of this emission has not yet been fully identified. Figure 2 also illustrates the stimulation spectrum measured while monitoring the $360 \mathrm{~nm}$ emission. The observed stimulation spectrum suggests that the OSL can be stimulated by light in a wide spectral range from approximately $550 \mathrm{~nm}$ to over $800 \mathrm{~nm}$. The stimulated spectrum curve has some noticeable features. Particularly around $800 \mathrm{~nm}$, the OSL stimulation is the most efficient among the spectral region tested. This indicates that the AlN has a large number of trapping center groups with different trapping depths. In the previous work, considerably shallow trapping centers were presented by TSL [19]; however, the OSL stimulation spectrum suggests a presence of deeper-but-stimulable charge trapping centers, especially those around $600 \mathrm{~nm}(\sim 2.0 \mathrm{eV})$.

Figure 3 shows a typical OSL decay curve of AlN ceramic, that is the transient OSL signal intensity during stimulation as a function of time. The stimulation light used here is $610 \mathrm{~nm}$, and the measured OSL emission signal is at $340 \mathrm{~nm}$. The decay curve can be decomposed into a sum of two exponential decay functions. The derived time constants are 20 and $155 \mathrm{~s}$. Since the decay curve can be decomposed well by only two exponential decay functions, this fact suggests that there are two groups of charge trapping centers mainly responsible for the OSL process involved here. Furthermore, the OSL curve in the shorter time range of 0-100 s, shown in the inset, clearly illustrates a transient increase of OSL signal between $0-3 \mathrm{~s}$, which is followed by an exponential decay. 
This transition behavior suggests the presence of shallow trapping centers [11]. In fact, our observation agrees with a thermoluminescence study reported earlier [19] that there exists a glow peak located at a considerably low temperature, $\sim 80^{\circ} \mathrm{C}$. Detailed analyses are beyond the scope of this paper; however, we plan on further investigations in order to understand the mechanism involved.

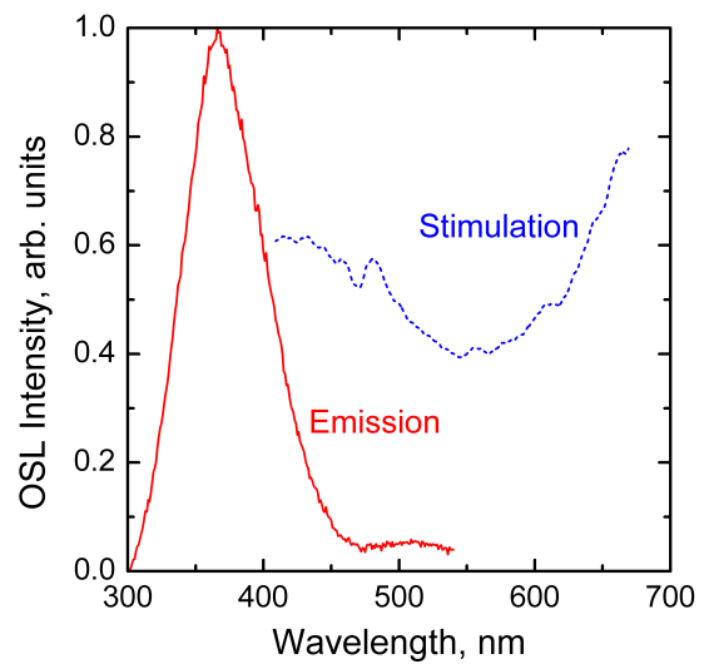

Figure 2. OSL emission and stimulation spectra of AlN ceramic. These spectra were measured after the sample was irradiated with $10 \mathrm{~Gy}$ of X-rays. The emission spectra were obtained by stimulation at $630 \mathrm{~nm}$ whereas the stimulation spectra were obtained by monitoring the emission at $360 \mathrm{~nm}$.

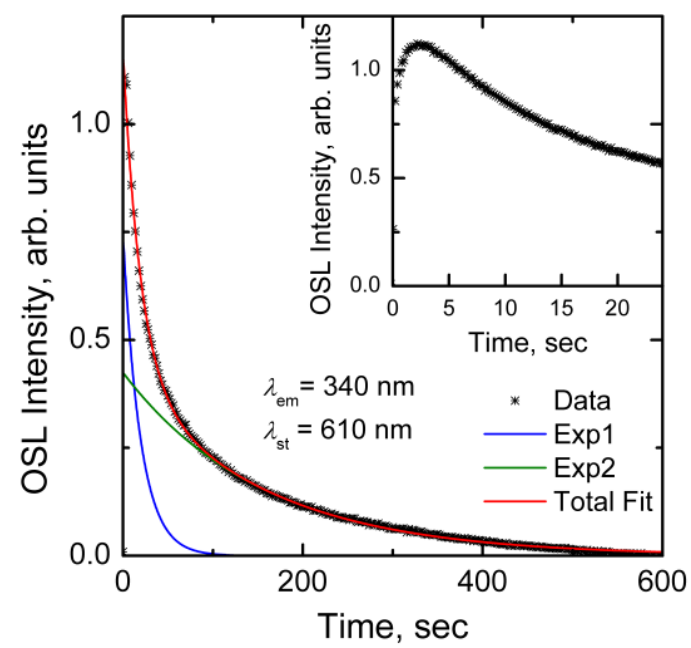

Figure 3. OSL decay curve. The OSL emission monitored is at $340 \mathrm{~nm}$ during a stimulation at $610 \mathrm{~nm}$ with a constant light intensity. The OSL curve can be approximated mainly by a sum of two exponential decay functions. The inset shows the OSL curve in a shorter time range $0-25 \mathrm{~s}$ after the stimulation started.

The OSL signal intensity increases with the X-ray dose irradiated. Figure 4 (left) illustrates the dose-response curve obtained when tested with X-rays. We have experimentally confirmed a linear response over four orders of magnitude without any saturation of the OSL signal. It is worth mentioning here that the dose response could not be tested for doses above 20 Gy due to the upper limit capability of our X-ray source. For lower doses, below $3 \mathrm{mGy}$, we could not successfully measure the OSL signal. It is instructive to mention here that the latter fact does not necessarily mean that the AlN ceramic plate does not have sufficient sensitivity below $3 \mathrm{mGy}$, but it can be due to the sensitivity of our experimental readout setup. The measurement capability of small doses is especially important 
for personnel dosimetry or medical imaging applications, while a dosimeter capable of large doses may find some applications such as radiation therapy [23-26].
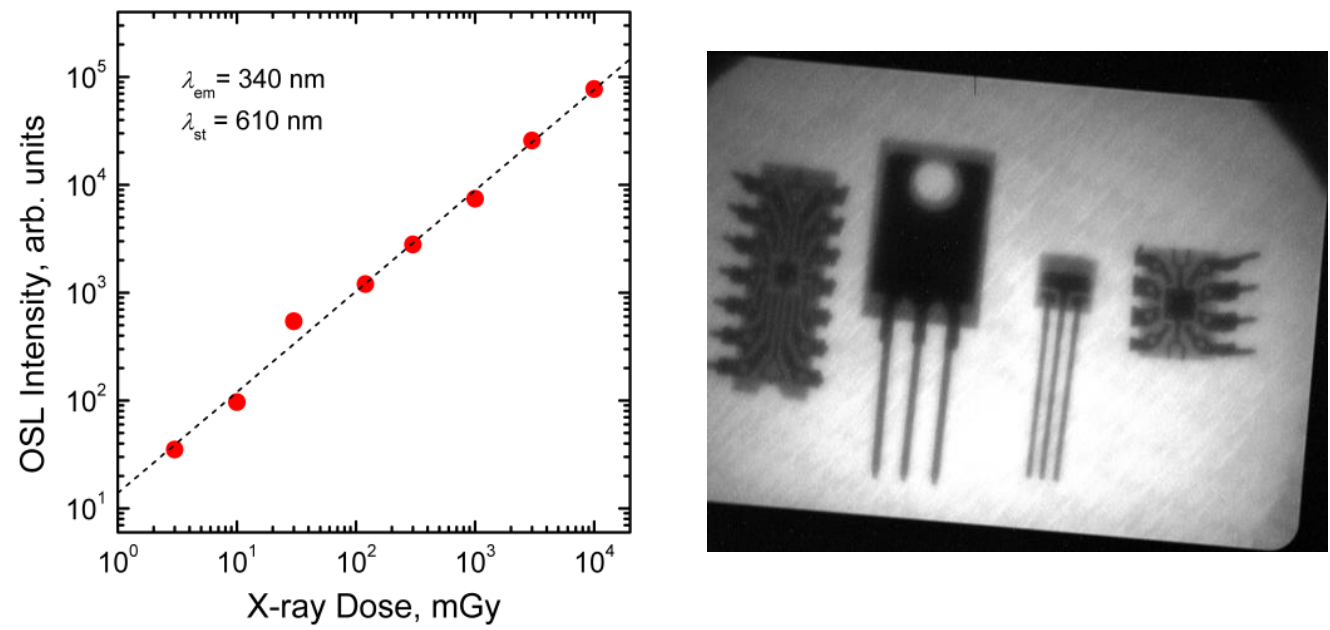

Figure 4. Experimental demonstrations of SHAPAL ${ }^{\circledR}$ AlN ceramic plate for use as an OSL dosimeter. (left) Dose response curve of OSL in an AlN ceramic plate. The stimulation light wavelength is $610 \mathrm{~nm}$ while the emission light is $340 \mathrm{~nm}$; (right) X-ray image of some electronic components taken by OSL of AlN ceramic plate. The stimulation light used here is $630 \mathrm{~nm} \pm 50 \mathrm{~nm}$. The electronic components are (from left to right): logic gate, field effect transistor, bipolar transistor, and operational amplifier.

Figure 4 (right) demonstrates an X-ray image taken on some electronic components using the SHAPAL ${ }^{\circledR}$ AIN ceramic plate. In the image, some electrodes and wiring hidden in the epoxy encapsulations are clearly observed. Although the setup is not fully optimized for high resolution imaging, our demonstration has shown that the legs of the bipolar transistor (the second part from the right-hand side in the image), which has the width of $0.5 \mathrm{~mm}$, are well resolved, and it indicates the spatial resolution is at least equivalent or better than $0.5 \mathrm{~mm}$. In addition, the uniformity of the image was tested with an image of a uniformly irradiated sample. The standard deviation was calculated to be 23.90 counts. This low value is mainly because of insufficient sensitivity of the CCD camera in the present measurement. A technique such as a flying-spot reader [5] should improve the signal-to-noise ratio since a photomultiplier tube has much better sensitivity to UV light. Overall, we think that the AlN ceramic plate has good potential to be used as an imaging plate for X-ray imaging applications.

\section{Conclusions}

In this research, we have discovered that an AIN ceramic plate $\left(\mathrm{SHAPAL}{ }^{\circledR}\right.$, Tokuyama Co, Yamaguchi, Japan) shows OSL, and we have investigated the OSL properties. The AIN ceramic plate is, in fact, designed and manufactured for heat sink applications; however, it has good potential to be used as an OSL storage phosphor for one- and two-dimensional dosimetry applications. By X-ray irradiation, the AlN ceramic plate turns in from a grey to yellowish color due to an X-ray-induced absorbance band appearing in the UV-blue range. With optical stimulation, an OSL emission can be observed in the UV region around $360 \mathrm{~nm}$ with a broad spectral feature. The OSL signal can be stimulated by light over a wide range of the spectrum from 400 to over $700 \mathrm{~nm}$, which is a distinct advantage. The OSL decay curve is a double-exponential, yielding two time constants (20 and $155 \mathrm{~s}$ ). However, a transient increase behavior is observed in the OSL immediately after the stimulation is given until $\sim 3 \mathrm{~s}$, followed by the exponential decay. This observation suggests the presence of shallow trapping centers in addition to the main dosimetric traps. The OSL dose response in the AlN ceramic plate has been demonstrated over 3 mGy-10 Gy. A two-dimensional dosimetry has also been successfully demonstrated with an imaging capability. 
Acknowledgments: This research was co-supported by a Grant-in-Aid for Scientific Research (A) (26249147), Grant-in-Aid for Research Activity start-up (15H06409), and Green Photonics Research from the Ministry of Education, Culture, Sports, Science and Technology of the Japanese government (MEXT). It is also partially supported by the Adaptable and Seamless Technology transfer Program (A-STEP) by the Japan Science and Technology (JST) Agency, the Murata Science Foundation, and a cooperative research project of the Research Institute of Electronics, Shizuoka University.

Author Contributions: e.g., Go Okada, Kentaro Fukuda, Safa Kasap, and Takayuki Yanagida conceived and designed the experiments; Kentaro Fukuda contributed the materials; Go Okada performed the experiments, analyzed the data, and wrote the paper.

Conflicts of Interest: The authors declare no conflict of interest.

\section{References}

1. Knoll, G.F. Radiation Detection and Measurement, 4th ed.; Wiley: New York, NY, USA, 2010.

2. Yanagida, T. Study of rare-earth-doped scintillators. Opt. Mater. 2013, 35, 1987-1992. [CrossRef]

3. Seeley, Z.; Cherepy, N.; Payne, S. Two-step sintering of $\mathrm{Gd}_{03} \mathrm{Lu}_{16} \mathrm{Eu}_{01} \mathrm{O}_{3}$ transparent ceramic scintillator. Opt. Mater. Express 2013, 3, 908-912. [CrossRef]

4. Drozdowski, W.; Brylew, K.; Wojtowicz, A.J.; Kisielewski, J.; Świrkowicz, M.; Łukasiewicz, T.; de Haas, J.T.M.; Dorenbos, P. 33000 photons per $\mathrm{MeV}$ from mixed $\left(\mathrm{Lu}_{075} \mathrm{Y}_{025}\right)_{3} \mathrm{Al}_{5} \mathrm{O}_{12}: \operatorname{Pr}$ scintillator crystals. Opt. Mater. Express 2014, 4, 1207-1212. [CrossRef]

5. Rowlands, J.A. The physics of computed radiography. Phys. Med. Biol. 2002, 47, R123-R166. [CrossRef] [PubMed]

6. Nanto, H.; Nishimura, A.; Kuroda, M.; Takei, Y.; Nakano, Y.; Shoji, T.; Yanagita, T.; Kasai, S. X-ray imaging plate using CsBr:Eu phosphors for computed radiography. Nucl. Instrum. Methods Phys. Res. Sect. A Accel. Spectrom. Detect. Assoc. Equip. 2007, 580, 278-281. [CrossRef]

7. Belev, G.; Okada, G.; Tonchev, D.; Koughia, C.; Varoy, C.; Edgar, A.; Wysokinski, T.; Chapman, D.; Kasap, S. Valency conversion of samarium ions under high dose synchrotron generated X-ray radiation. Phys. Status Solidi 2011, 8, 2822-2825. [CrossRef]

8. Miyamoto, Y.; Ohno, T.; Takei, Y.; Nanto, H.; Kurobori, T.; Yanagida, T.; Yoshikawa, A.; Nagashima, Y.; Yamamoto, T. Optical properties in $\mathrm{Ag}^{+}$-doped phosphate glass irradiated with $\mathrm{X}$-rays and $\alpha$-particles. Radiat. Meas. 2013, 55, 72-74. [CrossRef]

9. McKeever, S.W.S. Thermoluminescence of Solids; Cambridge University Press: New York, NY, USA, 1988.

10. McKeever, S.W.S. Optically stimulated luminescence dosimetry. Nucl. Instrum. Methods Phys. Res. Sect. B Beam Interact. Mater. Atoms 2001, 184, 29-54. [CrossRef]

11. Yukihara, E.G.; McKeever, S.W.S. Optically Stimulated Luminescence; John Wiley \& Sons, Ltd: Chichester, UK, 2011.

12. Kalnins, C.A.G.; Ebendorff-Heidepriem, H.; Spooner, N.A.; Monro, T.M. Radiation dosimetry using optically stimulated luminescence in fluoride phosphate optical fibres. Opt. Mater. Express 2012, 2, 62-70. [CrossRef]

13. Kalnins, C.A.G.; Spooner, N.A.; Ebendorff-Heidepriem, H.; Monro, T.M. Luminescent properties of fluoride phosphate glass for radiation dosimetry. Opt. Mater. Express 2013, 3, 960-967. [CrossRef]

14. Zimmerman, D.W. Photo- and thermoluminescence of LIF: (Mg, Ti). Appl. Phys. Lett. 1967, 10, 82-84. [CrossRef]

15. Akselrod, M.S.; Kortov, V.S.; Kravetsky, D.J.; Gotlib, V.I. Highly Sensitive Thermoluminescent Anion-Deffective Alpha- $\mathrm{Al}_{2} \mathrm{O}_{3}: \mathrm{C}$ Single Crystal Detectors. Radiat. Prot. Dosim. 1990, 32, 15-20.

16. Mckeever, S.W.S.; Akselrod, M.S.; Colyott, L.E.; Larsen, N.A.; Polf, J.C.; Whitley, V. Characterisation of $\mathrm{Al}_{2} \mathrm{O}_{3}$ for use in thermally and optically stimulated luminescence dosimetry. Radiat. Prot. Dosim. 1999, 84, 163-168. [CrossRef]

17. Bulur, E.; Göksu, H.Y. OSL from BeO ceramics: New observations from an old material. Radiat. Meas. 1998, 29, 639-650. [CrossRef]

18. Taniyasu, Y.; Kasu, M.; Makimoto, T. An aluminium nitride light-emitting diode with a wavelength of 210 nanometres. Nature 2006, 441, 325-328. [CrossRef] [PubMed]

19. Yanagida, T.; Fujimoto, Y.; Kawaguchi, N.; Yanagida, S. Dosimeter properties of AlN. J. Ceram. Soc. Jpn. 2013, 121, 988-991. [CrossRef]

20. Morita, M.; Tsubouchi, K.; Mikoshiba, N. Optical Absorption and Cathodoluminescence of Epitaxial Aluminum Nitride Films. Jpn. J. Appl. Phys. 1982, 21, 1102-1103. [CrossRef] 
21. Youngman, R.A.; Harris, J.H. Luminescence Studies of Oxygen-Related Defects In Aluminum Nitride. J. Am. Ceram. Soc. 1990, 73, 3238-3246. [CrossRef]

22. Trinkler, L.; Berzina, B. Radiation induced recombination processes in AIN ceramics. J. Phys. Condens. Matter 2001, 13, 8931-8938. [CrossRef]

23. Okada, G.; Morrell, B.; Koughia, C.; Edgar, A.; Varoy, C.; Belev, G.; Wysokinski, T.; Chapman, D.; Kasap, S. Spatially resolved measurement of high doses in microbeam radiation therapy using samarium doped fluorophosphate glasses. Appl. Phys. Lett. 2011, 99, 121105. [CrossRef]

24. Okada, G.; Vahedi, S.; Morrell, B.; Koughia, C.; Belev, G.; Wysokinski, T.; Chapman, D.; Varoy, C.; Edgar, A.; Kasap, S. Examination of the dynamic range of Sm-doped glasses for high-dose and high-resolution dosimetric applications in microbeam radiation therapy at the Canadian synchrotron. Opt. Mater. 2013, 35, 1976-1980. [CrossRef]

25. Okada, G.; Ueda, J.; Tanabe, S.; Belev, G.; Wysokinski, T.; Chapman, D.; Tonchev, D.; Kasap, S. Samarium-doped oxyfluoride glass-ceramic as a new fast erasable dosimetric detector material for microbeam radiation cancer therapy applications at the canadian synchrotron. J. Am. Ceram. Soc. 2014, 97, 2147-2153. [CrossRef]

26. Vahedi, S.; Okada, G.; Koughia, C.; Sammynaiken, R.; Edgar, A.; Kasap, S. ESR study of samarium doped fluorophosphate glasses for high-dose, high-resolution dosimetry. Opt. Mater. Express 2014, 4, 1244-1256. [CrossRef]

(C) 2016 by the authors; licensee MDPI, Basel, Switzerland. This article is an open access article distributed under the terms and conditions of the Creative Commons Attribution (CC-BY) license (http:/ / creativecommons.org/licenses/by/4.0/). 